\title{
Filling the Corallian gap: New information on Late Jurassic marine reptile faunas from England
}

\author{
Davide Foffa, Mark T. Young, and Stephen L. Brusatte \\ Acta Palaeontologica Polonica 63 (2), 2018: 287-313 doi:https://doi.org/10.4202/app.00455.2018
}

Two of the best known Mesozoic marine reptile assemblages can be found in units deposited in the Jurassic Sub-Boreal Seaway of the UK: the late Middle Jurassic Oxford Clay Formation (OCF) and Late Jurassic Kimmeridge Clay Formation (KCF). They record two very differently structured faunas, but understanding the turnover between them is hampered by a gap in the fossil record that spans much of the Oxfordian, the so-called "Corallian gap". We provide a comprehensive review of specimens from the Corallian Group (CG) of the UK, which includes the first descriptions of several fossils, particularly teeth. We demonstrate that there is a severe reduction in observed marine reptile diversity during the Oxfordian, with several Callovian taxa well known from the OCF not persisting into the Corallian strata, including small-to-mid-sized pliosaurids and longirostrine teleosaurids. We do, however, find evidence that at least one member of each key OCF lineage (plesiosauroids, pliosaurids, ichthyosaurs, and thalattosuchians) survived into the Corallian interval, and that one keystone $\mathrm{KCF}$ lineage (the Torvoneustes line of metriorhynchid thalattosuchians) was present during this time, indicating an earlier radiation of this group than previously thought. We suggest that faunal turnover between the OCF and KCF may have been driven by environmental perturbations during the Oxfordian, which selectively removed small bodied pliosaurids and longirostrine teleosaurids from the Jurassic Sub-Boreal Seaway, but less affected metriorhynchids, plesiosauroids, and ophthalmosaurid ichthyosaurs. The preferential removal of taxa from the sub-Boreal realm may have helped facilitate the radiation of lineages that became dominant during the Late Jurassic.

Key words: Plesiosauria, Teleosauridae, Ophthalmosauridae, "Pliosaurus" grossouvrei, Torvoneustes, faunal turnover, Corallian gap, Jurassic, UK.

Davide Foffa [ㅁavide.foffa@ed.ac.uk], Mark T. Young [mark.young@ed.ac.uk ], Stephen L. Brusatte [Stephen.Brusatte@ed.ac.uk], School of GeoSciences, University of Edinburgh, Grant Institute, James Hutton Road, Edinburgh, Scotland EH9 3FE, UK. 
This is an open-access article distributed under the terms of the Creative Commons

Attribution License (for details please see creativecommons.org), which permits unrestricted use, distribution, and reproduction in any medium, provided the original author and source are credited.

FoF Full text $(1,525.1 \mathrm{kB})$ 